\title{
Controlled Release of Model Substances from pH-Sensitive Hydrogels
}

\author{
David Quintanar-Guerrero, ${ }^{1}$ Briza Nadyr Zorraquín-Cornejo, ${ }^{1}$ Adriana Ganem-Rondero, ${ }^{1}$ \\ Elizabeth Piñón-Segundo, ${ }^{1 *}$ María Guadalupe Nava-Arzaluz, ${ }^{1}$ and José Manuel Cornejo-Bravo ${ }^{2}$.
}

${ }^{1}$ División de Estudios de Posgrado (Tecnología Farmacéutica), Facultad de Estudios Superiores Cuautitlán, Universidad Nacional Autónoma de México. Av. $1^{\circ}$ de Mayo s/n, Cuautitlán Izcalli, Estado de México, México, C. P. 54740. elizabeth.pinonsegundo@gmail.com

${ }^{2}$ Facultad de Ciencias Químicas e Ingeniería, Universidad Autónoma de Baja California, Tijuana, Baja California, México, C.P. 22300.

Received October 21, 2008; accepted December 19, 2008

\begin{abstract}
H-Sensitive hydrogels of the poly(methacrylic acid-comethyl methacrylate) (MAA/MMA) type, 22/78 molar \% with different cross-linking percentages $(0.3$ and $0.5 \%)$ were synthesized. These gels were loaded with a model hydrophilic compound (dichlorobromophenol blue dye, DCBFB) with the aim of evaluating its release at different $\mathrm{pH}$ values $(1.2,5.0,6.8,7.4)$. The swelling degree and the release from these hydrogels are highly dependent on the $\mathrm{pH}$ of the dissolution medium and on the cross-linking degree. Scanning electron microscopy and differential scanning calorimetry studies demonstrated that part of the dye is embedded in crystal form within the hydrogel. The release profiles of the hydrogels assessed at $\mathrm{pH}=$ 6.8 and 7.4 were adjusted to the Higuchi model, regarding them as matrix delivery systems.

Keywords: Hydrogels, pH-sensitive polymers, Methacrylates, poly(methacrylic acid-co-methyl methacrylate).
\end{abstract}

\section{Introduction}

One of the mainstays in the research of new pharmaceutical forms is meeting the concepts of temporal distribution and spatial location $[1,2]$. Temporal distribution refers to the rate of delivery of the therapeutic agent, which should be sufficient and sustained for a predetermined time. Spatial location considers the idea of placing the dosage form at the site where the effect is required [3]. In the last few decades, several investigations have been reported using hydrogels as release platforms in which the active therapeutic agents are withheld within the cross-linked macromolecular meshes, and are transferred to the dissolution medium by the swelling of the system upon contact with biological fluids $[4,5,6]$. The rate and time of release can be controlled by the drug/polymer ratio or by the cross-linking degree of the polymer. Recent advancements in hydrogel synthesis methods have caused a new drive in the application of these systems for the development of new pharmaceutical forms, particularly of those hydrogels that exhibit a swelling behavior dependent on the conditions of the release medium $[7,8,9]$. The ability of these materials to exhibit quick changes dependent on factors such as $\mathrm{pH}$, temperature or ionic strength enables the release of active substances —including peptides and proteins - in a pulsatile way or in a region where the effect is required, with a specific release rate and maintaining therapeutic margins. Considering that physiological areas,
Resumen. Se sintetizaron hidrogeles $\mathrm{pH}$-sensibles del tipo poli(ácido metacrílico-co-metacrilato de metilo) (MAA/MMA) 22/78 \% molar con diferentes porcentajes de entrecruzamiento (0.3 y $0.5 \%)$. Estos geles fueron cargados con un compuesto hidrofílico modelo (azul de diclorobromofenol), con la finalidad de evaluar su liberación a diferentes pH's $(1.2,5.0,6.8,7.4)$. El grado de hinchamiento y la liberación a partir de estos hidrogeles presenta alta dependencia al pH del medio de disolución y al grado de entrecruzamiento. Estudios de microscopía electrónica de barrido y calorimetría diferencial de barrido demostraron que parte del colorante se encuentra embebido en forma de cristales dentro del hidrogel. Los perfiles de liberación de los hidrogeles evaluados a $\mathrm{pH}=6.8$ y 7.4 fueron ajustados al modelo de Higuchi, considerándolos como sistemas de liberación matriciales.

Palabras clave: Hidrogeles, polímeros $\mathrm{pH}$-sensibles, metacrilatos, poli(ácido metacrílico-co-metil metacrilato).

such as the gastrointestinal tract, have environments with different $\mathrm{pH}$ 's, hydrogels with a $\mathrm{pH}$-dependent swelling are very attractive for the development of controlled release systems $[10,11]$. It is believed that this response capacity to $\mathrm{pH}$ is due to the presence of ionizable side substituents at the main chain of the hydrogel. In the particular case of ionic hydrogels that contain acid groups, the swelling degree increases in basic dissolution media, while for hydrogels that contain basic groups, swelling increases in an acid dissolution medium [12].

In this study, poly(methacrylic acid-co-methyl methacrylate) (MAA/MMA) hydrogel discs, 22/78 molar \%, with different cross-linking degrees, were synthesized. The systems thus prepared were loaded with a labeling dye by using the swelling and drying technique with the purpose of determining the release mechanism and type at different $\mathrm{pH}$ values. The discs were also analyzed by differential scanning calorimetry and scanning electron microscopy in order to determine whether the marker is dissolved or dispersed in the hydrogel discs. The main objective of this study is to analyze the release of a model marker from MAA/MMA hydrogels, 22/78 molar $\%$, with two cross-linking degrees $(0.3$ and $0.5 \%)$, using media with different $\mathrm{pH}$ values $(1.2,5.0,6.8$, and 7.4). At the same time, this study intends to show the potential of these hydrogels for designing modulated polymeric systems for the release of active therapeutic agents with controlled and pulsatile delivery properties. 


\section{Results and Discussion}

As previously reported [13], methacrylic acid-derived polymers behave like hydrophilic systems. When these are crosslinked, they become insoluble, but are capable of swelling. This swelling is due to the ionization/deionization of carboxyl groups. At a low $\mathrm{pH}(\mathrm{pka}>\mathrm{pH})$, the carboxyl groups are non ionized; therefore, the mesh is in a collapsed state. At high $\mathrm{pH}$ values (pka $<\mathrm{pH}$ ), carboxyl groups repel each other, causing the swelling of the system (Figure 1). The phenomenon could also be explained by the Donnan effect proposed for membrane equilibrium. The loaded polymer is capable of attracting counterions, causing a chemical potential gradient. As a consequence of the difference in counterion concentration, the osmotic pressure within the polymer's domain exceeds that of the external solution, and therefore, the polymer is capable of swelling.

Figure 2 shows the increase of swelling ( $\mathrm{Sw}$ ) percentage as a function of time for the hydrogels prepared. Sw is expressed as the relationship of the hydrogel area at a $t$ time divided by the initial area $\left(\mathrm{Sw} \%=\mathrm{A}_{\mathrm{t}} / \mathrm{A}_{0}\right)$ 100). It can be observed that there is a connection between the increase of the observed area, the $\mathrm{pH}$ value, and the cross-linking degree. At acid $\mathrm{pH}$ 's $(\mathrm{pH}=1.0$ and $\mathrm{pH}=5.0)$ no swelling is observed, even after $1600 \mathrm{~h}$ of exposure to the medium. This is the reason why no data for these systems are shown in the graph. Figures $3 \mathrm{~A}$ and $3 \mathrm{~B}$ show that at $\mathrm{pH}=1.0$ and $\mathrm{pH}=5.0$, the polymer behaves as a lipophilic material.

With the analyzed cross-links $(0.3 \%$ and $0.5 \%)$, swelling zones were detected in gels subjected to basic pH's (6.8 and 7.4); these are shown in Figure 3 C, D, E, and F. This behavior indicates the presence of polymer chain relaxation due to the electrostatic repulsion exhibited by the carboxylic groups. The increased hydrogel's swelling was evidenced by an increase in weight caused by the system's water absorption and retention.

When swelling percentages were analyzed, very different behaviors were found (Figure 2). Considering the fundamental concepts of polymer physics, it was expected that gels with a greater cross-linking would swell more slowly due to the mechanical hindrance of polymer chains. However, this aspect could not be clearly appreciated since in some cases, a detachment of polymeric material from the disc's surface occurred. Four advance fronts were identified: a) solvent penetration, b) swelling, c) surface disintegration, and d) dye diffusion, which were considered in the release analysis. There was no significant swelling in the gel discs with a $0.3 \%$ cross-linking at a $\mathrm{pH}$ of 6.8 , although this was sufficient for releasing the dye. Maximum swelling was approximately $28 \%$, showing a radial form, and was achieved at $482 \mathrm{~h}$. A point type release occurred thereafter. The difference between the behavior of the gel discs with a $0.5 \%$ and $0.3 \%$ cross-linking at the same $\mathrm{pH}$ lies obviously in the physical hindrance that increases as the cross-linking percentage increases. It is also important to point out that the penetration front of the solvent is not homogeneous. Apparently, the solvent penetrates more intensely in some regions than in others; therefore, no formation of a

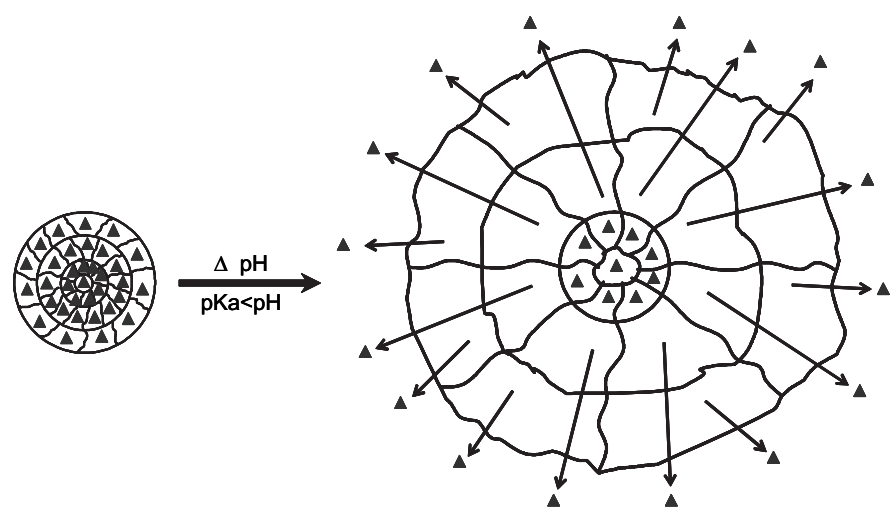

Fig. 1. Schematic representation of the behavior of a hydrogel with $\mathrm{pH}$-sensitive release. Modified from [5]. The triangles represent an active principle or a model compound trapped in the hydrogels, which starts to be released when the gel swells.

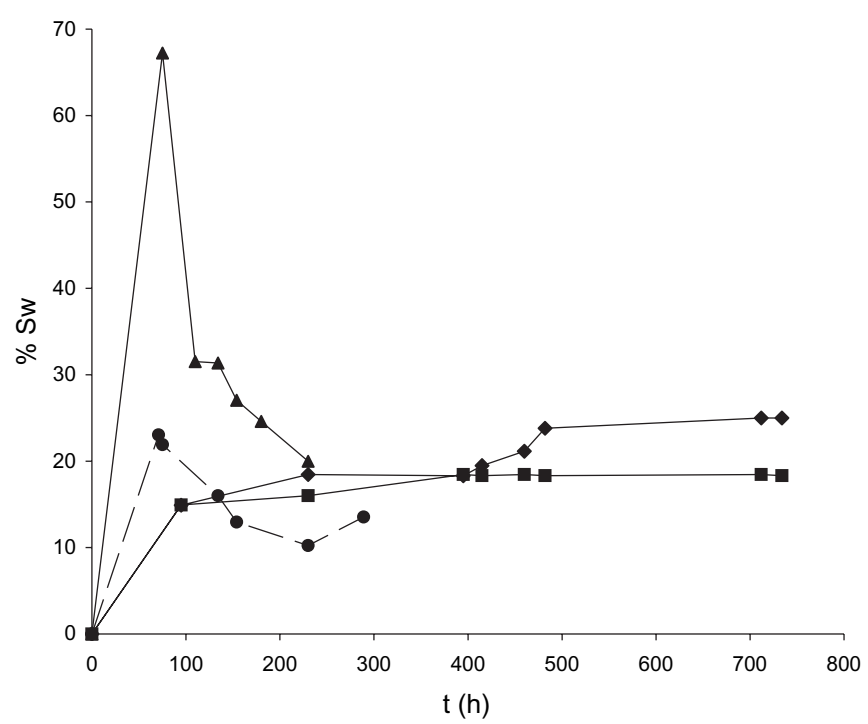

Fig. 2. Swelling percentage of MAA/MMA 22/78 molar \% hydrogels with different cross-linking percentages and subject to different $\mathrm{pH}$

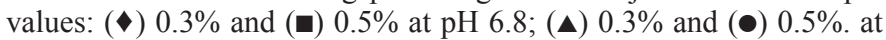
$\mathrm{pH}$ 7.4. $\mathrm{T}=37^{\circ} \mathrm{C}$. At $\mathrm{pH} 1.2$ and 5.0 no swelling was detected.

complete radial gummy layer was observed; this was only detected in localized regions with an appearance similar to that of "fractured glass", which breaks apart as a consequence of the growth of these relaxed intragel regions. In this sense, tortuosity plays an important role in the formation of these regions. It is important to note that the type of release for this cross-linking is directly related to this relaxation/disintegration form of penetration of the system, which apparently turns the system into a matrix with punctual drug regions. At a $\mathrm{pH}$ of 7.4, a quick swelling was observed in the gel discs with a $0.3 \%$ cross-linking, showing a peak at $80 \mathrm{~h}$, followed by a phenomenon in which the surface disintegration front has a decisive influence on the swelling percentage, and therefore, on release, since after $160 \mathrm{~h}$, radial release changes to a point 


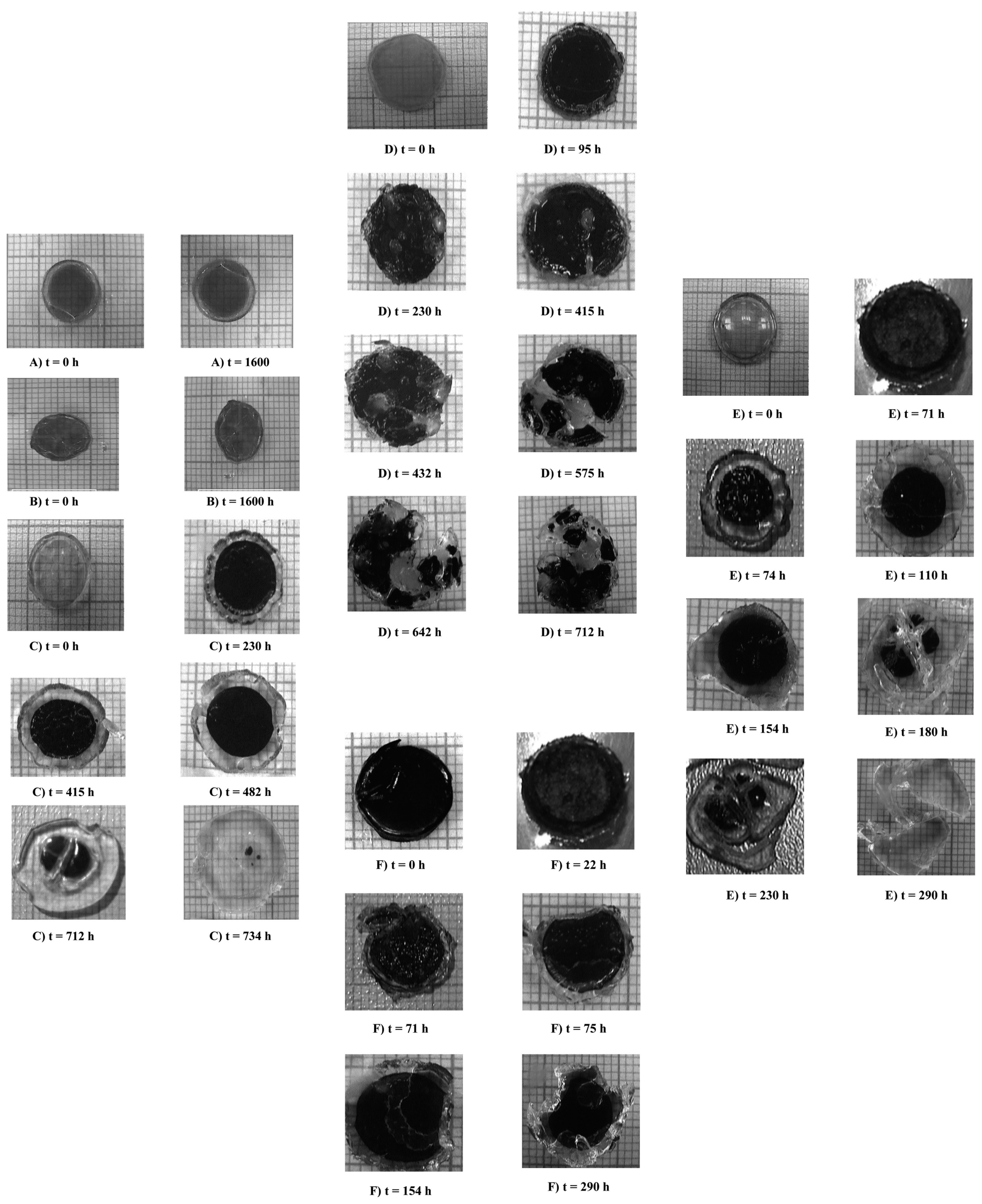

Fig. 3. Photographic sequence of swelling of MAA/MMA 22/78 molar $\%$ hydrogel with different cross-linking degrees and subject to different $\mathrm{pH}$ values: A) $0.3 \%$ at $\mathrm{pH} 1.2, \mathrm{~B}) 0.5 \% \mathrm{pH} 1.2, \mathrm{C}) 0.3 \%$ at $\mathrm{pH} 6.8, \mathrm{D}) 0.5 \%$ at $\mathrm{pH} 6.8, \mathrm{E}) 0.3 \%$ at $\mathrm{pH} 7.4, \mathrm{~F}) 0.5 \%$ at $\mathrm{pH} 7.4$. 
type release and an evident deformation and fracture of the polymer is noticed. For gel discs at a $\mathrm{pH}$ of 7.4 and with a $0.5 \%$ cross-linking, it was not possible to estimate swelling conclusively, since a rapid surface disintegration of the polymer was observed. Polymer disintegration is largely due to the mechanical opposition of the polymer to swelling and to the formation of localized relaxed regions. Apparently, due to mechanical limitations, the $0.5 \%$ cross-linking does not allow a controlled swelling of the system, and therefore, the release analysis cannot be interpreted with the disc's swelling.

Figure 4 shows the behavior of the gel layer's thickness during release. It can be observed that in basic dissolution media, the swelling band increases homogeneously. For most discs, and up to $250 \mathrm{~h}$, a linear and growing increase of the gel layer formation was observed. It is important to note that this increase was followed only until the loss of the radial release of the dye. The formation of this layer is dependent on $\mathrm{pH}$ and on cross-linking. At more alkaline conditions and at a lower cross-linking degree, the gel layer is formed more quickly. As mentioned previously, at a higher cross-linking, the physical counteraction of gel discs obstructs the solvent's permeation front, precluding the formation of this layer. For these systems, it was observed that at short times $(<230 \mathrm{~h})$ the nucleated release form was lost, and several irregular zones of dye release front were seen, where the penetration of the solvent was not radial and uniform, confirming the influence of the disintegration front on gel behavior and release.

Figure 5 shows the results obtained for the release of the DCBFB dye at the different $\mathrm{pHs}$ tested. In the acid dissolution media ( $\mathrm{pH} 1.2$ and 5.0), the hydrogels showed minimal dye release; less than $0.1 \%$ for gels with a $0.3 \%$ cross-linking, and lower than $0.01 \%$ for gels with a greater cross-linking degree. This released amount is attributed to the fraction of dye that is found in the surface and that is amenable to extraction by the penetration of the solvent through the exposed pores of the non-swollen disc. No subsequent release is observed due to the hydrophobic behavior of the system. The analysis by scanning electron microscopy (Figure 6) demonstrates that the internal structure of hydrogels is formed by an overlapping of polymer plates, where interconnected pores and channels are generated. The observation of different fields of the fractured regions of the gels allowed to evidence the presence of DCBFB crystals, which suggests that the system is a strict matrix. With the objective of confirming the presence of dye in its crystalline form, several differential scanning calorimetry assays were performed. Thermogram 1, included in Figure 7, was obtained for the DCBFB. It can be seen that two characteristic transitions occur: one at $\mathrm{H} \approx 130{ }^{\circ} \mathrm{C}$, corresponding to the presence of an amorphous structure, and one at $\mathrm{H} \approx 237{ }^{\circ} \mathrm{C}$, attributed to the dye's melting point. Thermogram 2 shows the behavior of MAA/MMA with a $0.3 \%$ cross-linking. The presence of a vitreous transition temperature of its amorphous zone, of nearly $77{ }^{\circ} \mathrm{C}$, can be observed, followed by a transition at 235 ${ }^{\circ} \mathrm{C}$, which is attributed to the presence of a minimal crystalline portion. When the gel loaded with the dye was analyzed (Thermogram 3), the vitreous transition temperature of the

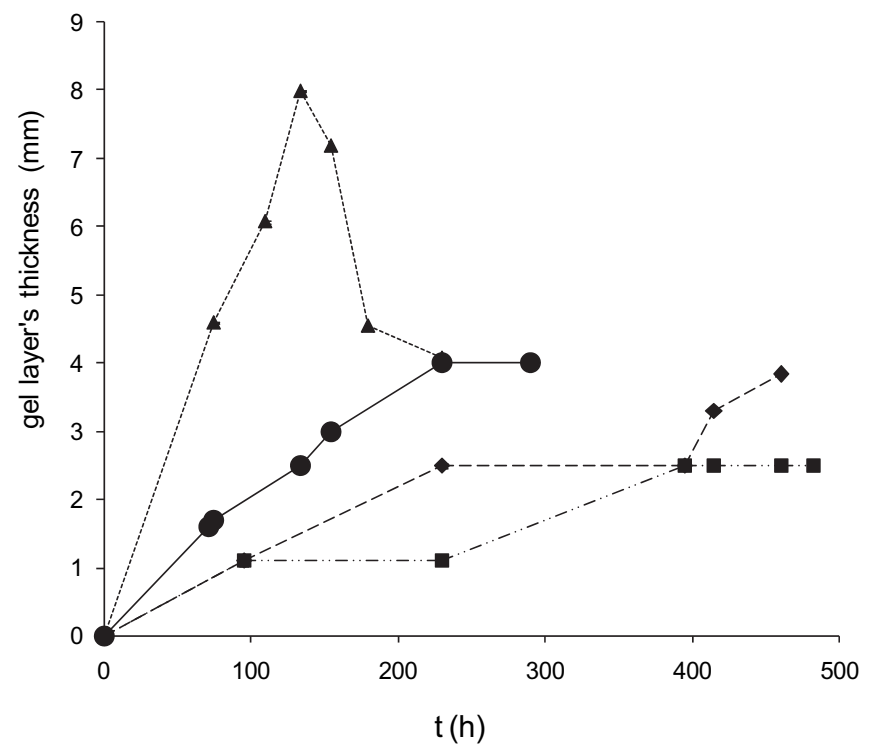

Fig. 4. Representation of the results of thickness advance of the gel zone in MAA/MMA 22/78 molar \% hydrogels with different crosslinking percentages subject to different $\mathrm{pH}$ values: ( $0.3 \%$ and (ם) $0.5 \% \mathrm{pH} 6.8,(\boldsymbol{\Delta}) 0.3 \%$ and $(\bullet) 0.5 \%$ at $\mathrm{pH} 7.4 .\left(\mathrm{T}=37^{\circ} \mathrm{C}\right)$.

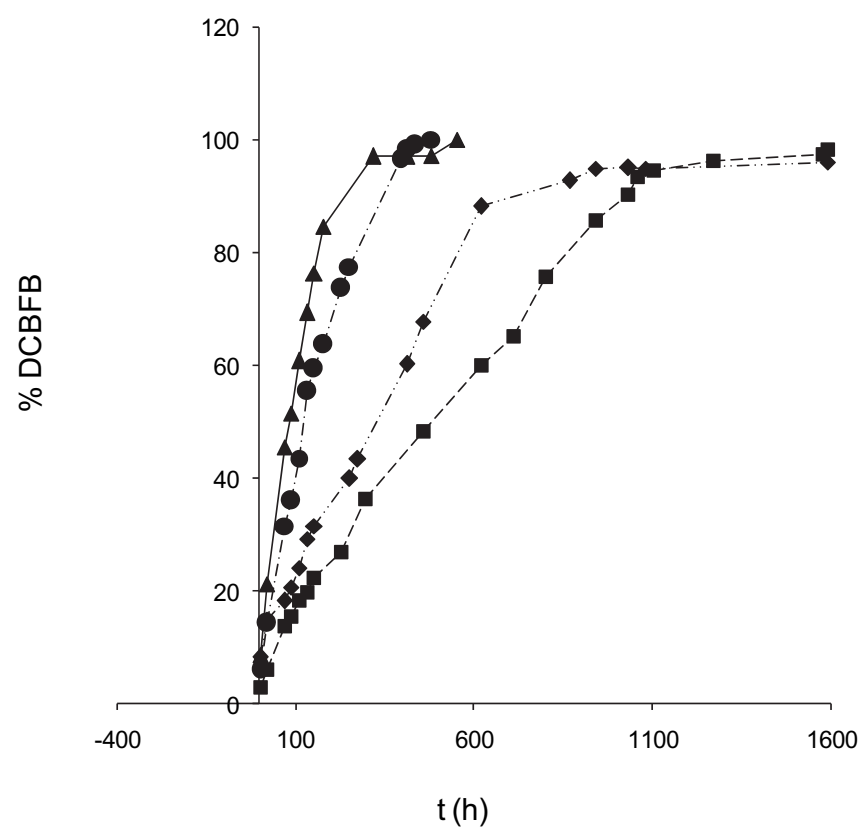

Fig. 5. DCBFB release profile in MAA/MMA 22/78 molar \% hydrogels with different cross-linking percentages in media with different

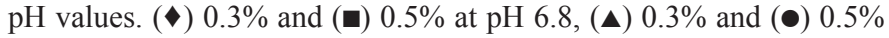
at $\mathrm{pH} 7.4\left(\mathrm{~T}=37^{\circ} \mathrm{C}\right)$. The fraction released at $\mathrm{pH} 1.2$ and 5.0 is minimal and is not detected in the graph.

polymer is observed, followed by a well defined endothermic signal attributed to the fusion of the dye.

Considering all of the above, as well as the results obtained by scanning electron microscopy, it is confirmed that the DCBFB is found completely or partially dispersed inside the gel's pores. The presence of the dye so dispersed has 

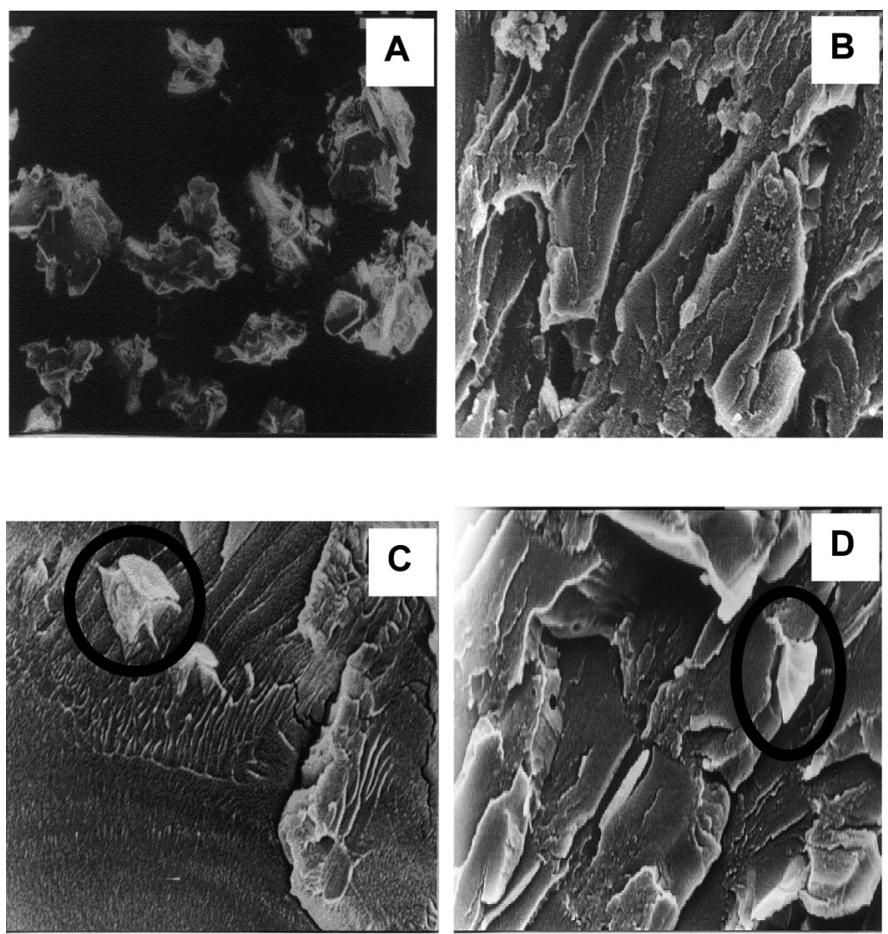

Fig. 6. Scanning electron micrographs of: A) DCBFB crystals (1500X). B) Internal structure of MAA/MMA 22/78 molar \% hydrogels with a $0.3 \%$ cross-linking (1500 X). C and D) MAA/MMA 22/78 molar \% hydrogels with a $0.3 \%$ cross-linking loaded with DCBFB (750 and $1500 \mathrm{X}$, respectively). The ovals show the presence of crystals inside the matrix.

important implications on the type and mechanism of release, since these crystals need to be dissolved within the matrix in order for the diffusion process to begin. Therefore, the rationalization of the release process calls for a deep analysis with the aim of distinguishing which advance front controls the dye's transference to the dissolution medium.

In the release profile included in Figure 5, a complete release of the dye was observed when the analysis is made with basic dissolution media $(\mathrm{pH}=6.8$ and 7.4). Two phases can be distinguished in the release profile: The first one corresponds to a linear phase with a previous burst effect. This rapid and quick release is attributed to the surface dye and to the quick outflow of the dye. These events take place before swelling of the first polymer layer. Some authors [14] have reported similar releases for this type of polymers and have attributed this behavior to a synchronization between the advance of the solvent's front, the rate of swelling, and the disintegration and/or dissolution of the polymer, which allows to have a radial and constant gummy layer thickness that controls the release and enables the formation of a constant diffusion gradient. This was not the case for our systems with regards to the analysis of the swelling process, since not all gummy layers were radial and homogeneous. The second phase observed in the release profiles corresponds to a drop in the release rate attributable to the increase of the hydrodynamic diffusion layer.

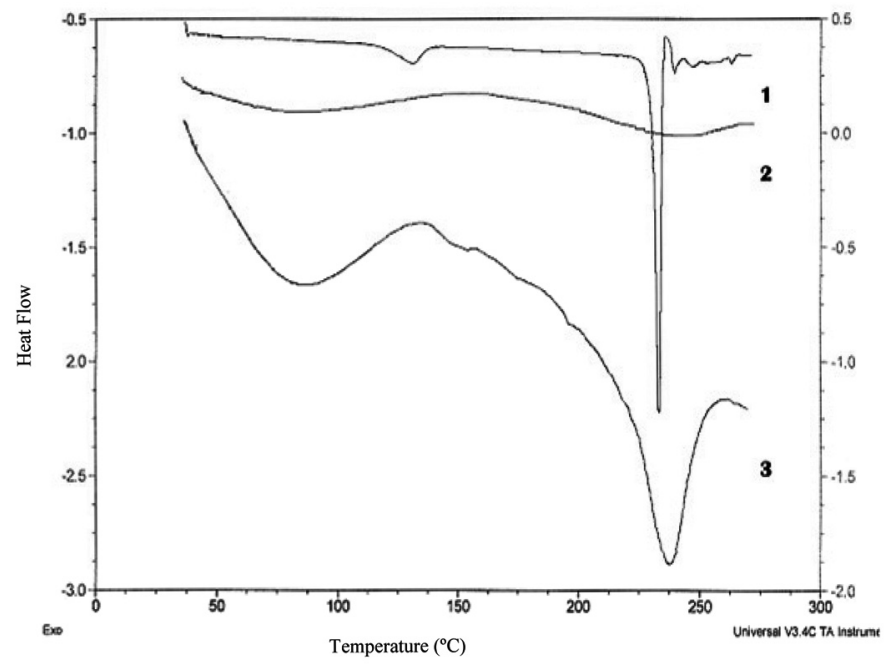

Fig. 7. Thermograms obtained by differential scanning calorimetry. 1) DCBFB (model dye). 2) MAA/MMA $22 / 78$ molar $\%$ with a $0.3 \%$ cross-linking without DCBFB. 3) MAA/MMA 22/78 molar \% with a $0.3 \%$ cross-linking loaded with DCBFB.

With the aim of discerning the possible mechanisms and types of release of the gels studied, the semi-empirical model proposed by Peppas $[14,15]$ was applied:

$$
d M t / d t=k t^{n-1}
$$

where $d M t / d t$ represents the release rate of the dye; $k$ is the Peppas constant, $\mathrm{t}$ is the time, and $n$ is the diffusion exponent indicative of the release mechanism and type. The equation was transformed to its logarithmic form and the release data were adjusted to this semi-empirical model. The $n$ value for each of the systems was obtained from the slope value (Table 2 ). The values obtained for $n$ are close to 0.5 , which indicates that all systems evaluated at a $\mathrm{pH}$ of 6.8 and 7.4 show a Fickian transport mechanism with a time-dependent release, $f\left(\mathrm{t}^{1 / 2}\right)$. From these parameters, we can determine that the system behaves very similarly to a non-erodible matrix system, where the hydrodynamic diffusion layer increases over time.

Higuchi $[14,15]$ developed an equation for the release of a drug from an ointment; this is applicable to the diffusion of solid drugs homogeneously dispersed in a matrix dosing system. The equation establishes that the release of a drug per area unit of a matrix-type system formed with a homogeneous polymer is proportional to the square root of time:

$$
Q=K_{H} t^{1 / 2}
$$

where $\mathrm{K}_{\mathrm{H}}$ is the Higuchi constant expressed as $(2 \mathrm{ADCs})^{1 / 2}$, where $\mathrm{A}$ is the diffusion area, $\mathrm{D}$ is the diffusion coefficient, and Cs is the drug's solubility in the system. By applying this equation to our systems (Table 2), we find that all fit acceptably $\left(r^{2}>0.97\right)$. Thus, we can affirm that this model explains the way in which the gel's active agents are transferred, without involving swelling phenomena, although it is clear 
Table 1. Systems used in release tests of DCBFB from MAA/MMA $22 / 78$ molar $\%$ hydrogels.

\begin{tabular}{ccc}
\hline System & \% Cross-linking & $\mathrm{pH}$ \\
\hline 1 & 0.3 & 1.2 \\
2 & 0.5 & 1.2 \\
3 & 0.3 & 5.0 \\
4 & 0.5 & 5.0 \\
5 & 0.3 & 6.8 \\
6 & 0.5 & 6.8 \\
7 & 0.3 & 7.4 \\
8 & 0.5 & 7.4 \\
\hline
\end{tabular}

Table 2. Values of $n, K_{H}$ and correlation coefficient $\left(r^{2}\right)$ for DCBFB release from MAA/MMA 22/78 molar \% hydrogels in basic media using the Peppas and Higuchi models.

\begin{tabular}{ccccccc}
\hline System & \% Cross-linking & $\mathrm{pH}$ & $n$ & $r^{2}$ & $K_{H}$ & $r^{2}$ \\
\hline 5 & 0.3 & 6.8 & 0.35 & 0.940 & 0.0057 & 0.997 \\
6 & 0.5 & 6.8 & 0.58 & 0.976 & 0.0040 & 0.971 \\
7 & 0.3 & 7.4 & 0.53 & 0.989 & 0.0097 & 0.987 \\
8 & 0.5 & 7.4 & 0.58 & 0.980 & 0.0084 & 0.991 \\
\hline
\end{tabular}

that they do govern the kinetics of the active agent's outflow. Apparently, the fact of having the active agent dispersed in the matrix and the effects of gel disintegration cause a growing increase of the swelling region during release, even in cases where the release is non-radial. The remaining disintegration fronts, and specially the erosion front, only control the intensity of release.

\section{Materials and methods}

\section{Synthesis of the poly(methacrylic acid-co-methyl methacrylate) (MAA/MMA) 22/78 molar \% hydrogel dises}

The poly(methacrylic acid-co-methyl methacrylate) (MAA/ MMA) $22 / 78$ molar \% hydrogels with two different crosslinking degrees $(0.3$ and $0.5 \%)$ were synthesized by the method described by Siegel et al. [7] and Cornejo Bravo et al [1]. Briefly, methacrylic acid (MAA) (Polysciences, USA), methyl methacrylate (MMA) (Polysciences, USA) and the crosslinking agent ethylene glycol dimethacrylate (EGDMA) (Polysciences, USA) were purified by passing them through a column of inhibitor-remover for hydroquinone and hydroquinone monomethyl ester (Aldrich). The free radical initiator 2,2' azo-bis-isobutyronitrile (AIBN) (Polysciences, USA) was purified by re-crystallization from methanol.

A mixture containing $8.05 \mathrm{~g}$ (0.081 mole) MMA, 1.96 $\mathrm{g}(0.023$ mole $)$ MAA and $0.05 \mathrm{~g}$ of $\operatorname{AIBN}(0.5 \% \mathrm{w} / \mathrm{w})$ was added with either $0.03 \mathrm{~g}(0.3 \% \mathrm{w} / \mathrm{w})$ or $0.05 \mathrm{~g}(0.5 \% \mathrm{w} /$ w) of EGDMA. This mixture was degasified under vac- uum and placed in glass molds previously silanized ( $2 \%$ $\mathrm{v} / \mathrm{v}$ dichloromethyl silane in toluene) with a 1-mm thickness. Polymerization was performed at $70{ }^{\circ} \mathrm{C}$ under a nitrogen atmosphere. After several hours, the hydrogel formed was removed and cut in discs $1 \mathrm{~cm}$ in diameter. The discs were collapsed in a water/methanol 50:50 (v/v) mixture, and were dried for 24 hours at room temperature and for 6 hours at $60{ }^{\circ} \mathrm{C}$ under vacuum.

\section{Incorporation of the dye to the gel discs}

The discs were loaded using the swelling and drying method, with a dichlorobromophenol blue dye (DCBFB) (Merck Mexico) that was used as marker compound. The discs were immersed in a methanol solution saturated with DCBFB $(\mathrm{H} \approx 2 \mathrm{mg} / \mathrm{mL})$ for $12 \mathrm{~h}$, and were subsequently dried at room temperature for $6 \mathrm{~h}$, and finally at $40{ }^{\circ} \mathrm{C}$ for $12 \mathrm{~h}$. The excess dye on the disc's surface was removed by immersing the discs in distilled water for 2 min and by repeating the drying process.

\section{Scanning Electron Microscopy (SEM) Studies}

A dye sample was dried at $20{ }^{\circ} \mathrm{C}$ for $12 \mathrm{~h}$ and placed on a sample-holding cylinder with adhesive carbon tape (Structure, USA). The hydrogels were fractured by half with the help of a cutting die and were placed on edge in a sample holding cylinder covered with a gold layer with a thickness of $20 \mathrm{~nm}$ and placed in a JFC-1100 chamber (JEOL, Japan). The samples were then observed with a scanning electron microscope JSM25 SII (JEOL, Japan).

\section{Differential Scanning Calorimetry (DSC) Studies}

The dye was dried at $20^{\circ} \mathrm{C}$ for $12 \mathrm{~h}$ and homogenized with the help of a mortar. The hydrogels with different cross-linking molar percentages were also pulverized. Approximately 3-5 $\mathrm{mg}$ of each sample were weighted on non-hermetic aluminum trays that were analyzed under the following conditions: heating rate of $5{ }^{\circ} \mathrm{C} / \mathrm{min}$, in a 35 to $274{ }^{\circ} \mathrm{C}$ range with a nitrogen atmosphere (flow $=50 \mathrm{~mL} / \mathrm{mn}$ ) in a DSC Q10 calorimeter (TA Instruments, USA).

\section{Study of DCBFB release from hydrogel discs}

DCBFB (model dye) release from hydrogels with two different cross-linking degrees was tested using an USP-II-type dissolution apparatus (Dissolution Tester DT1, Optimal Control) at a constant temperature of $37{ }^{\circ} \mathrm{C}$ and a stirring speed of $50 \mathrm{rpm}$. The volume of the dissolution medium was $500 \mathrm{ml}$. The dissolution media used were Simulated Intestinal Fluid (SIF), $\mathrm{pH}=$ 6.8 and $\mathrm{pH}=7.4$; Simulated Gastric Fluid (SGF) $\mathrm{pH}=1.2$; and a buffer solution of sodium biphtalate, $\mathrm{pH}=5.0$. SIF and SGF without enzymes were prepared according to United States Pharmacopeia XXIX. Table 1 sumarizes the $\mathrm{pH}$ values of the media used in the release. The study was followed up for 2 months, taking samples every $3 \mathrm{~h}$ the first day and then every 
David Quintanar-Guerrero et al.

24 hours until completing 1600 hours, replenishing the volume of the sample with the same medium. The samples were analyzed with a spectrophotometer (VarianCary 50, Australia) at $590 \mathrm{~nm}(\mathrm{pH}=5.0,6.8$, and 7.4) or at $434.9 \mathrm{~nm}(\mathrm{pH}=1.2)$. At the same time, the systems were weighted and photographed (HandyCam Sony, USA) on millimetric paper with the purpose of assessing the swelling percentage, the formation of the gummy layer, and the diffusion boundary of the dye in the gel $[16,17]$. It is important to point out that swelling was followed until the loss of integrity of the disc due to disintegration. The swelling percentage $(\mathrm{Sw} \%)$ is the percent relationship between the area at a given time $\left(\mathrm{A}_{\mathrm{t}}\right)$ and the initial area $\left(\mathrm{A}_{0}\right)$; $\mathrm{Sw} \%=\left(\mathrm{A}_{\mathrm{t}} / \mathrm{A}_{0}\right) 100$.

\section{Conclusions}

Polyacid hydrogels are an interesting option for designing controlled-release pharmaceutical forms responding to the $\mathrm{pH}$ of the physiological cavity in which they are administered. The release of the active agent for this type of systems is promoted in basic media by the ionization of the carboxyl groups. Since the response in different regions of the body is dependent on $\mathrm{pH}$, this type of gels become intelligent systems, with a response in those sites where the effect is required (vectorization). This study showed that it is possible to control the release of active agents for prolonged periods of time by modifying the polymer's cross-linking. The $\mathrm{pH}$-sensitive gels prepared show a release that can be described as a strict matrix or whose release is influenced by the formation of a growing gel layer. Active agent's release from polyacid $\mathrm{pH}$-sensitive gels is dependent on the advance of four fronts involved in the process: a) solvent penetration, b) swelling, c) surface disintegration, and d) diffusion of the active agent. Among these, swelling is the factor that defines the mechanism and type of release. The synthesized gels behave as matrix systems that adjust to the Higuchi model $\left(t^{1 / 2}\right)$. Cross-linking plays a fundamental role in the physical behavior of the systems and in dissolution kinetics. According to the evidence presented, the gels prepared show a high porosity, where the active agent is trapped in the form of crystals.

\section{Acknowledgements}

The authors would like to acknowledge the technical assistance of Rodolfo Robles in the scanning electron microscopy studies.

\section{References}

1. Cornejo, B. J.M.; Orozco H.A. Proceed. Int'l. Symp. Control. Rel. Bioact. Mater Soc. 2001, 28, 299-300.

2. Peppas, N.A. "Swelling controlled release systems. Recent developments and applications" in: Controlled Drug Delivery, Müller, B.W., Ed., Wissenschaftliche Verlagsgesellschaft, Stuttgart, 1987, 161-178.

3. Robinson, J.R.; Lee, L., Controlled Drug Delivery. Marcel Dekker, New York, 1987.

4. Lowman, A.M.; Peppas, N.A. "Hydrogels" in: Encyclopedia of Controlled Drug Delivery, Vol. 1, Mathiowitz, E., Ed., John Wiley \& Sons, New York, 1999, 397-418.

5. Escobar, J.L.; García, D.M.; Zaldivar, D.; Katime, I. Rev. Iber. Polim. 2002, 3, 1-15.

6. Yong Qiu, K.P. Advanced Drug Delivery Reviews 2001, 53, 321339.

7. Siegel, R. A.; Falamarzian, M.; Firestone, B.A.; Moxley, B. J. Control. Rel. 1988, 8, 179-182.

8. García, D.M.; Escobar, J.L.; Bada, N.; Casquero, J.; Hernáez, E.; Katime, I. Eur. Polym. J. 2004, 40, 1637-1643.

9. García, D.M.; Escobar, J.L.; Noa, Y.; Bada, N.; Hernáez, E.; Katime, I. Eur. Polym. J. 2004, 40, 1683-1690.

10. Peppas, N.A.; Bures, P.; Leobandung, W.; Ichikawa, H. Eur. J. Pharm. Biopharm. 2000, 50, 27-46.

11. Sáez, V.; Hernáez, E.; Sanz, L. Rev. Iber. Polim. 2003, 4, 21-91.

12. Dinh, S.M.; DeNuzzio, J.D.; Comfort, A.R. Intelligent Materials for Controlled Release. ACS., New York, 1999.

13. Peppas, N.A.; Mikos, A.G. "Preparation methods and structure of hydrogels" in: Hydrogels in medicine and pharmacy. Fundamentals, Vol 1, Peppas, N.A., Ed., CRC Press, Florida, 1986.

14. Masaro, L.; Zhu, X. Prog. Polym. Sci. 1999, 24, 731-775.

15. Narasimhan, B.; Mallapragada, S.K.; Peppas, N.A. «Release kinetics, data interpretation» in: Encyclopedia of Controlled Drug Delivery, Vol. 2, Mathiowitz, E., Ed., John Wiley \& Sons, New York, 1999, 921-935.

16. Quintanar-Guerrero, D.; Ganem-Quintanar, A.; Raygoza-Trejo, D.; Doelker, E. Drug Dev. Ind. Pharm. 1999, 25, 169-174.

17. Quintanar-Guerrero, D.; Villalobos-García, R.; Álvarez-Colín, E.; Cornejo-Bravo, J.M. Biomaterials. 2001, 22, 957-961. 